\title{
Effects of Combined Estrogen and Progestin Administration on Plasma Lipoprotein Metabolism in Postmenopausal Women
}

\author{
Bernard M. Wolfe and Murray W. Huff \\ Department of Medicine, University Hospital, and The University of Western Ontario, London, Ontario, Canada N6A 5 A5
}

\begin{abstract}
Treatment of postmenopausal women with low doses of estradiol-17 $\beta(1 \mathrm{mg} / \mathrm{d})$ and $d l$-norgestrel $(0.75 \mathrm{mg} / \mathrm{d})$ significantly reduced fasting serum levels of low density lipoprotein (LDL) cholesterol and lowered very low density lipoprotein (VLDL) triglycerides in four of five subjects. To explain these results, the kinetics of VLDL and LDL apolipoprotein (apo) B turnover were studied by injecting autologous ${ }^{125}$ I-labeled VLDL and ${ }^{131} \mathrm{I}$-labeled LDL into subjects before discontinuing longterm (4-yr) treatment with the estradiol-17 $\beta$ and $d l$-norgestrel and again 7 wk after stopping treatment. The $24 \%$ mean decrease in VLDL apo $B$ pool size during treatment was associated with a significant increase in VLDL apo $B$ fractional catabolic rate (15 \pm 1 vs. $11 \pm 1$ pools/d), whereas production rate was similar to control ( $24 \pm 3 \mathrm{vs.} 21 \pm 2 \mathrm{mg} / \mathrm{kg}$ per d). There was a significant $25 \%$ mean decrease in $L D L$ apo $B$ pool size $(27 \pm 2$ vs. $36 \pm 3 \mathrm{mg} / \mathrm{kg})$ due to a significant decrease in total $(8.3 \pm 0.3 \mathrm{vs} .11 \pm 1 \mathrm{mg} / \mathrm{kg}$ per d) and independent $(3.3 \pm 0.5 \mathrm{vs}$. $6.6 \pm 0.8 \mathrm{mg} / \mathrm{kg}$ per $\mathrm{d}, P<0.05) \mathrm{LDL}$ apo $B$ production. Estradiol-17 $\beta$ together with $d l$-norgestrel lowered plasma VLDL by enhancing their clearance and LDL by reducing their production.
\end{abstract}

\section{Introduction}

Currently $90 \%$ of women survive to reach the menopause, including over 30 million American women with an average postmenopausal life expectancy of 28 years (1). When ovarian secretion of estradiol and progesterone ceases (2), the concentration of serum cholesterol rises $(3,4)$, and women lose their relative immunity, as compared with men, from coronary artery disease (5). Simultaneously, the incidences of bone fractures associated with osteoporosis (6) and of deaths from female cancers rise sharply (7). Heart attacks and underlying coronary artery disease become major causes of death and disability, causing four times as many deaths among women as cancer of the breast and endometrium combined (8). Retrospective studies suggest that estrogens could possibly halve the risk of death from ischemic heart disease in postmenopausal women (9).

A preliminary report of this research has been published in abstract form (1987. Arteriosclerosis. 7:501a).

Address reprint requests to Dr. Bernard M. Wolfe, Division of Endocrinology and Metabolism, Department of Medicine, University Hospital, London, Ontario, Canada N6A 5A5.

Received for publication 14 December 1987 and in revised form 4 August 1988.

J. Clin. Invest.

(c) The American Society for Clinical Investigation, Inc

$0021-9738 / 89 / 01 / 0040 / 06 \$ 2.00$

Volume 83, January 1989, 40-45
Although high doses of estrogen alone increase serum triglycerides (10), Wolfe and Plunkett have reported that treatment with combined low doses of estradiol-17 $\beta$ and $d l$-norgestrel significantly lowers both serum triglyceride and cholesterol levels in postmenopausal women (11). 18 subjects receiving this regimen for $3 \mathrm{yr}$ had an average reduction of fasting serum total cholesterol of $19 \%$, low density lipoprotein (LDL) ${ }^{1}$ cholesterol of $23 \%$, total triglycerides of $31 \%$, and very low density lipoprotein (VLDL) triglycerides of $31 \%(P<0.025)$; these were associated with a favorable decrease of $14 \%$ in the ratio of LDL cholesterol: high density lipoprotein cholesterol (Plunkett, E. R., and B. M. Wolfe, unpublished observations). The effects of these low doses of estradiol-17 $\beta$ and $d l$-norgestrel on the kinetics of apolipoprotein (apo) B metabolism of plasma VLDL and LDL of postmenopausal women are the subject of this report.

\section{Methods}

Subjects. Five participants were recruited from University Hospital outpatient clinics (Table I). Each experienced typical menopausal symptoms and was amenorrheic for at least $6 \mathrm{mo}$ (serum follicle-stimulating hormone $>70 \mathrm{U} /$ liter) before starting hormonal replacement therapy with estradiol- $17 \beta(1 \mathrm{mg} / \mathrm{d}, 25$ of $28 \mathrm{~d})$ and $d l$-norgestrel $(0.75$ $\mathrm{mg} / \mathrm{d}, 28$ of 28 d) 4 yr earlier. Fasting serum cholesterol and triglyceride concentrations exceeded the 95th percentile in two subjects (11), and cholesterol concentration alone was elevated in one subject before treatment. At the end of the 4-yr period of therapy with estradiol-17 $\beta$ and $d l$-norgestrel five subjects volunteered for studies of the kinetics of VLDL- and LDL apo B turnover. Each subject underwent a turnover study immediately before discontinuing the medication and again 7 wk after stopping the medication and completing the first study. During the present study the subjects were maintained on conventional diets containing $\sim 15 \%$ protein, $45 \%$ carbohydrate, and $40 \%$ fat ( $<500 \mathrm{mg}$ cholesterol/d). They were admitted to the hospital and given low-fat diets $(<5 \mathrm{~g}$ fat/d, $62 \mathrm{~g}$ protein, and $378 \mathrm{~g}$ carbohydrate consisting of $2 \%$ milk fat cottage cheese, cereals, juices, gelatin, and skim milk) during the first day of each of their turnover experiments. Subjects received no other medications known to affect lipid metabolism, and intake of ethanol was $<30 \mathrm{ml} / \mathrm{d}$ for the month before each turnover study. All subjects had normal fasting concentrations of serum glucose, glutamic oxaloacetic transaminase, thyroxine, creatinine, calcium, albumin, sodium, potassium, chloride, and bicarbonate. Hematological and urine analyses were normal. The experimental protocol that had been approved by the Standing Committee on Human Research of the University of Western Ontario was explained to each subject and informed consent was obtained in writing. All subjects received $300 \mathrm{mg}$ potassium iodide daily for $3 \mathrm{~d}$ before and for $13 \mathrm{~d}$ after the reinjection of their radiolabeled lipoproteins.

Preparation of labeled lipoproteins and kinetic studies. Fasting blood plasma ( $1.5 \mathrm{mg}$ EDTA/ml) for isolation of VLDL and LDL was obtained from each subject $6 \mathrm{~d}$ before each turnover study. The proce-

1. Abbreviations used in this paper: apo, apolipoprotein; FCR, fractional catabolic rate(s); IDL, intermediate density lipoprotein(s); LDL, low density lipoprotein(s); VLDL, very low density lipoprotein(s). 
Table I. Characteristics of Subjects

\begin{tabular}{|c|c|c|c|c|c|c|c|}
\hline \multirow[b]{2}{*}{ Subject } & \multirow[b]{2}{*}{ Age } & \multirow[b]{2}{*}{ Height } & \multirow[b]{2}{*}{ Weight } & \multicolumn{2}{|c|}{ Cholesterol } & \multicolumn{2}{|c|}{ Triglycerides } \\
\hline & & & & Control & Treated & Control & Treated \\
\hline & $y r$ & $\mathrm{~cm}$ & $k g$ & \multicolumn{4}{|c|}{$m g / d l$} \\
\hline 1 & 63 & 159 & 62 & 263 & 228 & 181 & 155 \\
\hline 2 & 55 & 159 & 76 & 290 & 205 & 301 & 181 \\
\hline 3 & 55 & 175 & 77 & 213 & 190 & 120 & 112 \\
\hline 4 & 63 & 155 & 60 & 174 & 139 & 112 & 95 \\
\hline 5 & 51 & 155 & 77 & 155 & 147 & 95 & 146 \\
\hline Mean & 57 & 161 & 70 & 219 & $182^{*}$ & 162 & 138 \\
\hline$\pm \mathrm{SE}$ & 2 & 4 & 4 & 26 & 17 & 44 & 15 \\
\hline
\end{tabular}

* Significantly different from control, $P<0.05$.

dures used for the preparation of the labeled lipoproteins have been previously described (12-15). Plasma chylomicrons $\left(S_{f}>400\right)$ were not detectable visually after centrifuging the plasma at $17,000 \mathrm{rpm}$ at $12^{\circ} \mathrm{C}$ for $30 \mathrm{~min}$. VLDL $\left(\mathrm{S}_{\mathrm{f}} 60-400\right)$ were isolated from plasma by ultracentrifugation at $40,000 \mathrm{rpm}$ at $12^{\circ} \mathrm{C}$ for $2 \mathrm{~h}$ in a $60 \mathrm{Ti}$ rotor (Beckman Instruments, Inc., Palo Alto, CA), and washed first in a swinging bucket SW $40 \mathrm{Ti}$ rotor at $40,000 \mathrm{rpm}$ at $12^{\circ} \mathrm{C}$ for $2 \mathrm{~h}$, and then in a $50 \mathrm{Ti}$ rotor at $40,000 \mathrm{rpm}$ at $12^{\circ} \mathrm{C}$ for $18 \mathrm{~h}$. LDL $\left(\mathrm{S}_{\mathrm{f}} 0-12\right)$ were isolated from the plasma infranatant at $d=1.063$ (60 Ti rotor) at $50,000 \mathrm{rpm}$ for $18 \mathrm{~h}$ at $12^{\circ} \mathrm{C}$ after removing the $\mathrm{S}_{\mathrm{f}}>12$ lipoproteins by centrifugation at $d=1.019$ (50 Ti rotor) at $40,000 \mathrm{rpm}$ for $18 \mathrm{~h}$ at $12^{\circ} \mathrm{C}$. They were washed once by recentrifugation under the same conditions $(d=1.063)$. VLDL and LDL were radiolabeled with ${ }^{125} \mathrm{I}$ and ${ }^{131}$ I (Amersham Canada Ltd., Oakville, ON), respectively. $95 \%$ of the radioisotope ${ }^{125} I$ was bound to VLDL protein, $1 \%$ was associated with lipids, and 3\% remained unbound; VLDL apo B accounted for $46 \%$ of the ${ }^{125}$ I bound to VLDL protein. $98 \%$ of the radioisotope ${ }^{131} I$ was bound to LDL protein, $1 \%$ was associated with lipids, and $1 \%$ remained unbound; LDL apo B accounted for $92 \%$ of the ${ }^{131} I$ bound to LDL protein.

Experimental protocol. Each recipient fasted $12 \mathrm{~h}$ before receiving serially $100 \mu \mathrm{Ci}$ of ${ }^{125}$ I-labeled VLDL and $30 \mu \mathrm{Ci}$ of ${ }^{131}$ I-labeled LDL in 2-3 ml of normal saline over $2 \mathrm{~min}$ via a hand or forearm vein. Venous blood samples (each $20 \mathrm{ml}, 1.5 \mathrm{mg}$ EDTA/ml) were obtained over $16 \mathrm{~d}$ at $0.5,1,2,4,6,8,10,12,24,48,72,120,216,288$, and $384 \mathrm{~h}$ after injection and placed on ice before immediate separation of lipoproteins. VLDL $\left(S_{\mathrm{f}} 60-400\right)$, IDL $\left(S_{\mathrm{f}} 12-60\right)$, and LDL $\left(S_{\mathrm{f}} 0-12\right)$ were isolated as previously described $(12,16)$. VLDL were washed once by recentrifugation. Apo $B$ was isolated from each lipoprotein fraction by isopropanol precipitation and its specific activity determined (17).

Analyses. As in rats receiving $d$-norgestrel alone (15), the specific activity curves of VLDL apo B were better described by a three-pool than a two-pool model (Fig. 1). The kinetic parameters of the threepool model for ${ }^{125} \mathrm{I}-\mathrm{VLDL}$ apo B were calculated using a correction (15) of the method of Goodman et al. (18) according to Skinner (19). However, there was little difference between the three-pool and twopool models for the decay of radioactivity in ${ }^{131}$ I-LDL apo B, and both yielded curves that were similar to the observed values (Fig. 1). Thus, the specific activity curves of LDL apo B were analyzed and kinetic parameters calculated using the conventional two-pool model of Gurpide et al. $(12,20-22)$. This yielded values for flux rates through pool 1 , irreversible fractional catabolic rate ([FCR] $F C R=k_{A}$, assuming that flux from other pools is negligible; 22), and the mass in pool 1 . The FCR was calculated as: $\mathrm{k}_{\mathrm{A}}=\alpha \beta /\left(\alpha+\beta-\mathrm{k}_{\mathrm{AA}}\right)$ (22). The precursorproduct relationships between VLDL, IDL, and LDL were analyzed according to Zilversmit (23). The percent of LDL apo B that was not derived from IDL apo B was calculated as: 1 - (area under the ${ }^{125} \mathrm{I}$ LDL apo B specific activity curve/area under the ${ }^{125}$ I-IDL apo B spe- cific activity curve $) \times 100(14,24)$. Concentrations of cholesterol and triglycerides in the chloroform-methanol extract of plasma were determined as previously described (13). Variation in lipoprotein, apo B, and lipid concentrations and kinetics between control and treatment periods were assessed using the paired $t$ test (25).

\section{Results}

Treatment with the combined estradiol-17 $\beta$ and $d l$-norgestrel consistently lowered serum cholesterol and decreased fasting triglycerides in four of the five subjects (Table I). These changes were associated with corresponding alterations in the concentrations of lipids in VLDL, IDL, and LDL (Table II).

Values for the specific activities of ${ }^{125}$ I-labeled apo B in VLDL, IDL, and LDL over $72 \mathrm{~h}$ after injection of ${ }^{125} \mathrm{I}$-labeled VLDL during control vs. treatment with estradiol-17 $\beta$ and $d l$-norgestrel in a representative subject are shown in Fig. 2 . The kinetic parameters of VLDL turnover calculated from the ${ }^{125}$ I-labeled VLDL apo B decay curves are shown in Table III. Based on these curves the half-lives of phases 1 and 2, but not 3 , were consistently shorter during treatment vs. control. The FCR of VLDL apo B (15) was significantly increased, by an average of $36 \%$, during treatment (15 vs. 11 pools/d). This increase in the efficiency of VLDL apo B catabolism accounted for the $24 \%$ decrease in the size of the pool of VLDL apo B because production was unchanged ( $24 \mathrm{vs.} 21 \mathrm{mg} / \mathrm{kg}$ per d). Fig. 3 illustrates the effect of treatment on the percent decrease of the ${ }^{125}$ I-labeled VLDL apo B specific activity from the plasma for a representative subject. The mean values for the half-lives of phase I $(0.5$ vs. $0.8 \mathrm{~h}, 0.05<P<0.10)$ and phase II ( 1.5 vs. $2.1 \mathrm{~h}, 0.05<P<0.10)$ of the decay curves for VLDL apo B were appreciably shorter during treatment vs. control, indicating that treatment enhanced fractional clearance of VLDL apo B (Table III).

Values for the kinetic parameters of LDL turnover calculated from the ${ }^{131} \mathrm{I}$-labeled LDL apo B decay curves using the two-pool model of Gurpide et al. (20-22) are shown in Table IV. LDL apo B pool size was significantly decreased with treatment $(27 \pm 1.9$ vs. $36 \pm 4.3 \mathrm{mg} / \mathrm{kg}, P<0.005)$. This was attributable to the significant decrease in total LDL apo B production $(8.3 \pm 0.3$ vs. $11 \pm 1.1 \mathrm{mg} / \mathrm{kg}$ per $\mathrm{d}, P<0.025)$ as there was no change in the FCR of LDL apo B.

Examination of precursor-product relationships (23) between lipoprotein fractions indicated that VLDL were the sole precursors of IDL. As illustrated in a representative subject (Fig. 2), the decay curves of VLDL apo B consistently intersected those of IDL apo B at their peaks during both treatment and control. However, the LDL apo B specific activity curves consistently reached their peaks before they were intersected by their corresponding IDL curves. This is consistent with the view that not all LDL were derived from IDL catabolism (23). Comparisons of the areas under the specific activity curve as described by Goldberg et al. (24) indicated that LDL production derived via the direct pathway decreased by $50 \%$ during treatment $(3.3 \pm 0.5$ vs. $6.6 \pm 0.8 \mathrm{mg} / \mathrm{kg}$ per $\mathrm{d}, P<0.05)$. There was no change in the rate of LDL apo $B$ production derived indirectly via IDL catabolism during treatment vs. control $(5.0 \pm 0.6$ vs. $4.4 \pm 0.5 \mathrm{mg} / \mathrm{kg}$ per d, respectively). In four of five subjects a higher fraction of LDL was derived from IDL (via the indirect pathway) during treatment vs. control (60 vs. $41 \%$, $0.05<P<0.10$ ). 
SUBJECT 2

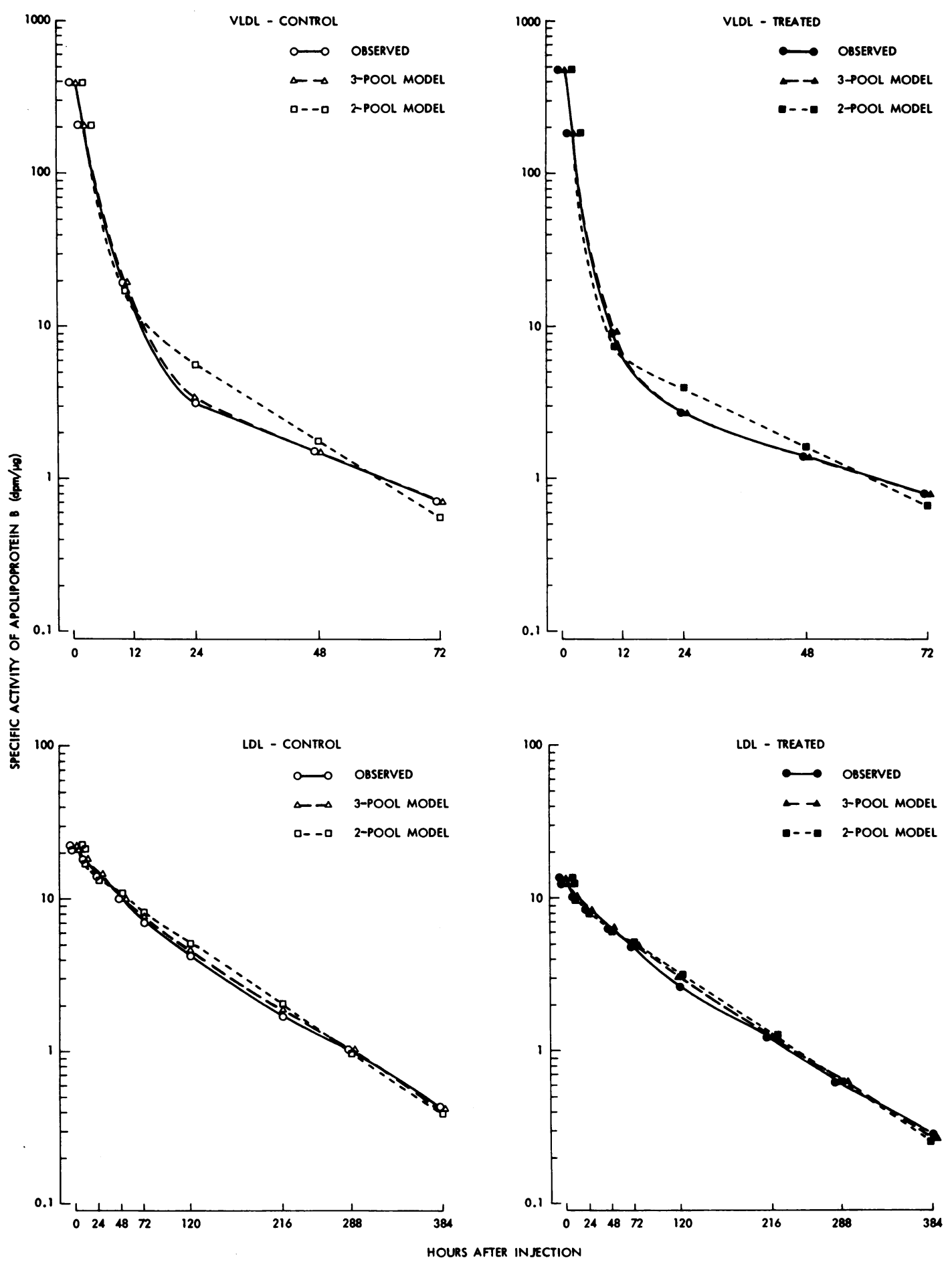

Figure 1. Specific activities of $(a)$ apo B of VLDL after intravenous injections of autologous ${ }^{125}$ I-labeled VLDL (top) and $(b)$ apo B of LDL after intravenous injections of autologous ${ }^{131}$ Ilabeled LDL (bottom) during each control and treatment period for a representative subject (subject 2). The curves for the observed values (circles) are compared with those obtained with a three-pool model (triangles) and a twopool model (squares).

\section{Discussion}

The present studies provide new insights into the mechanisms whereby sex hormones modulate the concentrations of serum lipoproteins. The lowering of serum triglycerides (in four of five subjects) was consistent with the lowering of VLDL apo B pool size during treatment with estradiol-17 $\beta$ and $d l$-norgestrel (Table III). Because production rate was essentially unchanged, the decreased pool size was accompanied by a signifi- cant increase in the FCR of VLDL apo B. The present findings in postmenopausal women receiving estradiol-17 $\beta$ and $d l$-norgestrel are in accord with the finding of enhanced efficiency of clearance of VLDL apo B in intact female rats receiving only $d$-norgestrel at approximately twofold higher doses of active hormone per kg body wt $\mathrm{t}^{0.75}(15)$. Only the $d$-isomer of $d l$-norgestrel is biologically active. By contrast, ethinyl estradiol given alone in doses that are an order of magnitude higher in potency (26) than used in the present study were found to 
Table II. Effects of Estradiol-17\% and dl-Norgestrel on Fasting Levels of Serum Lipoproteins in Subjects Undergoing Turnover Studies

\begin{tabular}{|c|c|c|c|c|c|c|c|c|c|c|}
\hline \multirow[b]{3}{*}{ Subject } & \multirow{2}{*}{\multicolumn{2}{|c|}{$\begin{array}{c}\begin{array}{c}\text { Tri- } \\
\text { glycerides }\end{array} \\
\text { VLDL } \\
\end{array}$}} & \multicolumn{8}{|c|}{ Cholesterol } \\
\hline & & & \multicolumn{2}{|c|}{ VLDL } & \multicolumn{2}{|c|}{ IDL } & \multicolumn{2}{|c|}{ LDL } & \multicolumn{2}{|c|}{ HDL } \\
\hline & C & $\mathbf{R x}$ & C & $\mathbf{R x}$ & C & $\mathbf{R x}$ & C & $\mathbf{R x}$ & C & $\mathbf{R}$ \\
\hline & \multicolumn{10}{|c|}{$m g / d l$} \\
\hline 1 & 85 & 65 & 19 & 14 & 22 & 16 & 201 & 168 & 43 & 40 \\
\hline 2 & 163 & 86 & 36 & 19 & 23 & 14 & 224 & 153 & 31 & 33 \\
\hline 3 & 51 & 36 & 17 & 12 & 24 & 20 & 155 & 135 & 43 & 43 \\
\hline 4 & 65 & 25 & 12 & 12 & 8 & 8 & 108 & 85 & 54 & 43 \\
\hline 5 & 30 & 48 & 15 & 11 & 14 & 9 & 108 & 101 & 33 & 37 \\
\hline Mean & 79 & 52 & 20 & 14 & 18 & 13 & 159 & $128^{*}$ & 41 & 39 \\
\hline$\pm \mathrm{SE}$ & 23 & 11 & 4 & 1 & 3 & 2 & 24 & 16 & 4 & \\
\hline
\end{tabular}

* Mean values during treatment $(\mathrm{Rx})$ were significantly different from control (C), $P<0.05$.

double both the production and the plasma concentration of apo B of VLDL of $S_{f} 20-400$ in premenopausal women (10).

Two factors could explain why the low dose of estradiol-

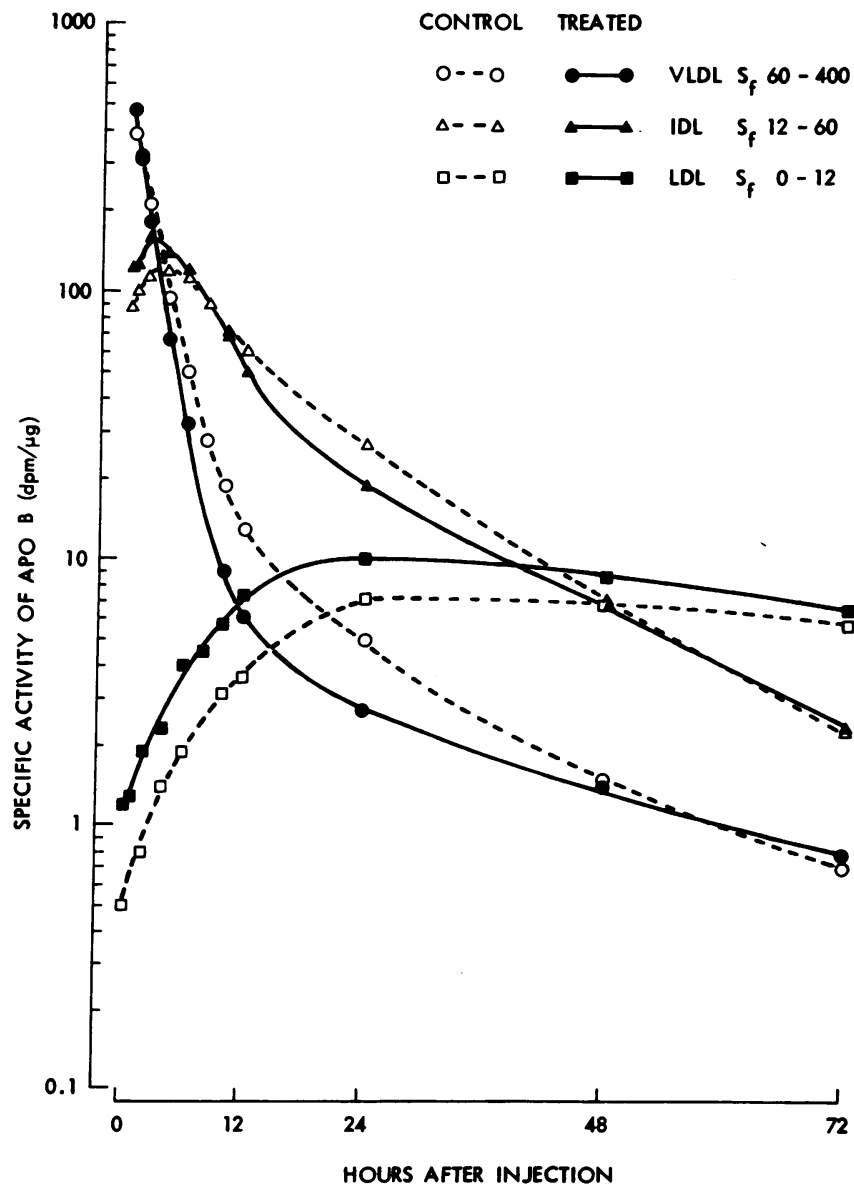

Figure 2. Specific activities of apo B of VLDL, IDL, and LDL after intravenous injection of autologous ${ }^{125}$ I-labeled VLDL during control (open symbols) and treatment (closed symbols) for subject 2.
Table III. Kinetic Parameters of Human ${ }^{125}$ I-VLDL Apo B Turnover in Estradiol-17 $\beta$ and dl-Norgestrel-treated Postmenopausal Subjects

\begin{tabular}{|c|c|c|c|c|c|c|c|}
\hline \multirow[b]{2}{*}{ Subject } & \multirow[b]{2}{*}{ Period } & \multicolumn{3}{|c|}{ Half-life of phase } & \multirow{2}{*}{$\begin{array}{c}\text { Fractional } \\
\text { catabolic } \\
\text { rate }\end{array}$} & \multirow{2}{*}{$\begin{array}{c}\text { Pool } \\
\text { size of } \\
\text { VLDL apo B }\end{array}$} & \multirow{2}{*}{$\begin{array}{l}\text { Production } \\
\text { rate }\end{array}$} \\
\hline & & I & II & III & & & \\
\hline & & & $h$ & & pools/d & $m g / k g$ & $m g / k g \cdot d$ \\
\hline \multirow[t]{2}{*}{1} & C & 1.0 & 1.8 & 26 & 8.0 & 3.0 & 24 \\
\hline & $\mathbf{R x}$ & 0.3 & 1.7 & 53 & 16 & 1.2 & 19 \\
\hline \multirow[t]{2}{*}{2} & $\mathrm{C}$ & 1.1 & 2.1 & 22 & 8.3 & 2.9 & 24 \\
\hline & $\mathbf{R x}$ & 0.5 & 1.5 & 26 & 13 & 1.7 & 22 \\
\hline \multirow[t]{2}{*}{3} & $\mathrm{C}$ & 0.5 & 1.8 & 30 & 11 & 1.9 & 22 \\
\hline & $\mathbf{R x}$ & 0.5 & 1.6 & 34 & 12 & 2.0 & 24 \\
\hline \multirow[t]{2}{*}{4} & $\mathrm{C}$ & 0.8 & 2.5 & 26 & 11 & 1.5 & 17 \\
\hline & $\mathbf{R x}$ & 0.7 & 1.6 & 19 & 16 & 2.2 & 35 \\
\hline \multirow[t]{2}{*}{5} & C & 0.8 & 2.6 & 28 & 15 & 1.2 & 18 \\
\hline & $\mathbf{R x}$ & 0.5 & 1.0 & 19 & 18 & 1.0 & 19 \\
\hline Mean & $\mathrm{C}$ & 0.8 & 2.2 & 26 & 11 & 2.1 & 21 \\
\hline$\pm \mathrm{SE}$ & & \pm 0.1 & \pm 0.2 & \pm 1 & \pm 1.2 & \pm 0.4 & \pm 1.5 \\
\hline Mean & $\mathbf{R x}$ & 0.5 & 1.5 & 30 & $15^{*}$ & 1.6 & 24 \\
\hline$\pm \mathrm{SE}$ & & \pm 0.06 & \pm 0.1 & \pm 6 & \pm 1.1 & \pm 0.2 & \pm 3.0 \\
\hline
\end{tabular}

* Significantly different from control, $P<0.05$.

$17 \beta$ did not systematically increase production of apo B of $S_{\mathrm{f}}$ $60-400$ in the present study. First, the dose of estradiol-17 $\beta$ was much smaller. Second, $d l$-norgestrel may have partially antagonized any estrogenic stimulation of hepatic VLDL secretion since VLDL apo B production was unchanged with treatment.

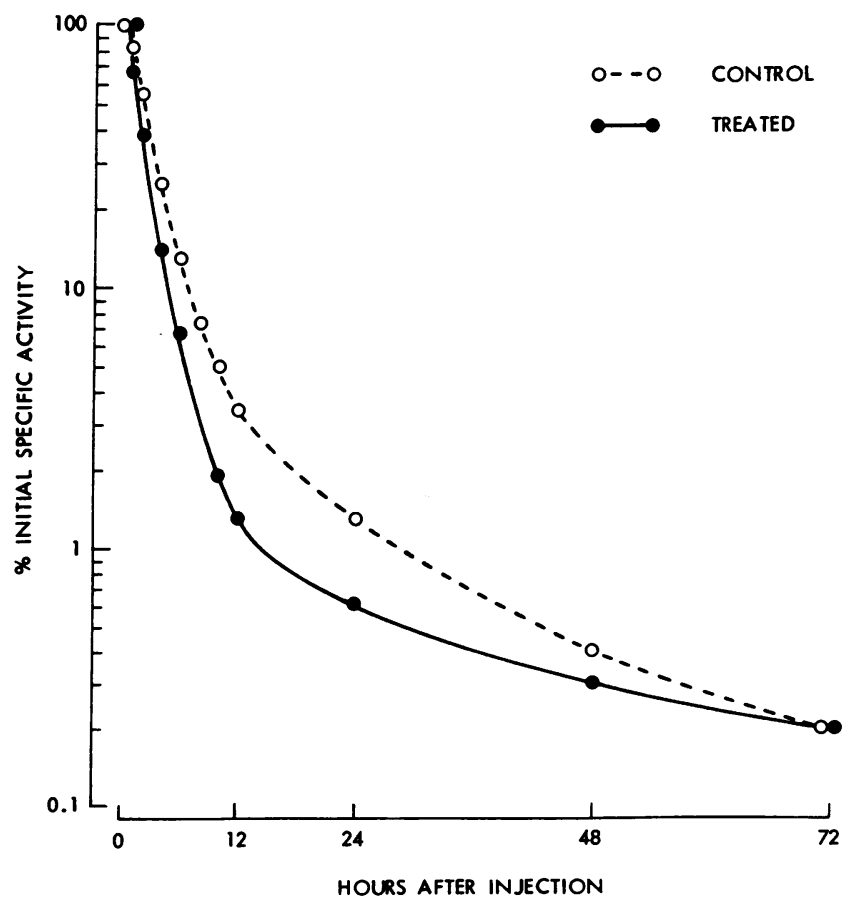

Figure 3. Specific radioactivity of VLDL apo B expressed as percent of the initial specific activity ( 30 min postinjection) after intravenous injection of autologous ${ }^{125}$ I-labeled VLDL for subject 2. 
Table IV. Kinetic Parameters of Human ${ }^{131}$ I-LDL Apo B Turnover in Estradiol-17ß and dl-Norgestrel-treated Postmenopausal Subjects

\begin{tabular}{|c|c|c|c|c|c|c|c|c|}
\hline \multirow[b]{2}{*}{ Subject } & \multirow[b]{2}{*}{ Period } & \multicolumn{2}{|c|}{ Half-life of phase } & \multirow{2}{*}{$\begin{array}{l}\text { Fractional } \\
\text { catabolic rate }\end{array}$} & \multirow[b]{2}{*}{ LDL apo B } & \multicolumn{2}{|c|}{ Production rate } & \multirow{2}{*}{$\begin{array}{l}\text { Fraction of LDL apo B } \\
\text { derived from IDL apo B }\end{array}$} \\
\hline & & I & II & & & Total & Direct & \\
\hline & & \multicolumn{2}{|c|}{$h$} & pools/d & $m g / k g$ & \multicolumn{2}{|c|}{$m g / k g \cdot d$} & $\%$ \\
\hline \multirow[t]{2}{*}{1} & $\mathrm{C}$ & 12 & 81 & 0.28 & 39 & 11 & 7.1 & 34 \\
\hline & $\mathbf{R x}$ & 16 & 93 & 0.28 & 31 & 8.6 & 4.6 & 47 \\
\hline \multirow[t]{2}{*}{2} & $\mathrm{C}$ & 23 & 90 & 0.31 & 47 & 15 & 8.3 & 43 \\
\hline & $\mathbf{R x}$ & 27 & 83 & 0.28 & 31 & 8.7 & 3.2 & 63 \\
\hline \multirow[t]{2}{*}{3} & $\mathrm{C}$ & 15 & 92 & 0.32 & 34 & 11 & 6.0 & 44 \\
\hline & $\mathbf{R x}$ & 18 & 77 & 0.31 & 27 & 8.2 & 3.1 & 62 \\
\hline \multirow[t]{2}{*}{4} & $\mathrm{C}$ & 18 & 90 & 0.33 & 35 & 12 & 7.8 & 32 \\
\hline & $\mathbf{R x}$ & 20 & 75 & 0.37 & 24 & 9.0 & 1.8 & 80 \\
\hline \multirow[t]{2}{*}{5} & $\mathrm{C}$ & 24 & 102 & 0.31 & 26 & 7.8 & 3.7 & 52 \\
\hline & $\mathbf{R x}$ & 27 & 80 & 0.34 & 21 & 7.2 & 3.8 & 47 \\
\hline Mean & $\mathrm{C}$ & 18 & 91 & 0.31 & 36 & 11 & 6.6 & 41 \\
\hline$\pm \mathrm{SE}$ & & \pm 2 & \pm 3 & \pm 0.02 & \pm 3.4 & \pm 1.2 & \pm 0.8 & \pm 4 \\
\hline Mean & $\mathbf{R x}$ & $22^{*}$ & 82 & 0.32 & $27^{*}$ & 8.3* & $3.3^{*}$ & 60 \\
\hline$\pm \mathrm{SE}$ & & \pm 2 & \pm 3 & \pm 0.01 & \pm 2.0 & \pm 0.3 & \pm 0.5 & \pm 6 \\
\hline
\end{tabular}

* Significantly different from control, $P<0.05$.

Little is known about the mechanisms of the interactions of estrogens and progestins on lipoprotein metabolism in women. Our findings in female rats do not completely parallel those in the human subjects (27), suggesting that intact rats may respond differently than postmenopausal women. Although estradiol abolished $d$-norgestrel inhibition of triglyceride synthesis in rat hepatocytes and antagonized the hypolipemic effect of $d$-norgestrel in intact female rats, $d$-norgestrel failed to reduce the serum triglyceride-elevating effects of estradiol (27). However, in these estrogen-deficient postmenopausal subjects, we found that serum triglycerides fell in four of five subjects during treatment with the combined hormones (Table I).

Studies in rats also indicated that $d$-norgestrel inhibited hepatic synthesis and release of VLDL triglycerides (28), in part by inhibition of the glycerol-3-phosphate acyltransferase (EC .2.3.1.15) step in hepatic triglyceride synthesis (29). However, VLDL apo B production in $d$-norgestrel-treated rats was not affected (15), consistent with the secretion of VLDL particles that contain less triglyceride. Plunkett and Wolfe have previously reported that in a larger group of postmenopausal women combined low doses of estradiol-17 $\beta$ and $d l$-norgestrel significantly lowered serum triglycerides (11). VLDL-triglycerides fell in four of five subjects during treatment in the present study (Table II). Taken together with the unchanged rates of production of VLDL apo B, these observations suggest that VLDL particles may have contained less triglyceride on the average during the treatment vs. the control period. Increased hepatic triglyceride lipase activity resulting from norgestrel administration (30) could also play a role in lowering VLDL and IDL levels by enhancing their removal from the plasma (31).

The decreased pool size of LDL apo B and the lower LDL cholesterol concentrations in the present study are explained by the observed reduction in LDL apo B production (Table IV). In previous studies, in rats treated with $d$-norgestrel alone, LDL pool size increased due to a decrease in fractional catabolic rate, whereas LDL apo B production was unchanged.
The present observations in postmenopausal women receiving both estradiol-17 $\beta$ and $d l$-norgestrel suggest that estradiol may neutralize the inhibitory properties of $d$-norgestrel on LDL apo B catabolism.

The molecular basis for the suppression of LDL apo B production by combined low doses of estrogen and progestin observed in the present study is unknown. There has been a paucity of studies of VLDL and LDL turnover in postmenopausal women. The present studies indicate that a substantial fraction of the LDL apo B secreted in postmenopausal women lacking estrogen and progesterone is produced via either a direct synthesis pathway $(14,24)$ or a very rapid pathway of conversion of VLDL to LDL that cannot be detected. Nevertheless, this pathway is suppressible by exogenous estrogen and progestin. We are unaware of previous studies of this pathway of LDL apo B metabolism in premenopausal women, so it cannot be determined at this time whether low-dose estradiol$17 \beta$ and $d l$-norgestrel restore the pattern of LDL apo B metabolism in postmenopausal to that of premenopausal women. However, Reardon et al. have reported a study in a postmenopausal Type III subject in whom a dose of estrogen $(0.75 \mathrm{mg}$ piperazine estrone sulphate/d) comparable to the present dose, had no effect on VLDL apo B production, but lowered IDL apo B production by one-third through abolition of the direct pathway of IDL apo B synthesis (32).

Drastic reductions of plasma LDL concentrations have been reported in rats receiving very large pharmacological doses of ethinyl estradiol; however, these changes in LDL concentration have been related to increases in the number of hepatic receptors for LDL (33). We found no evidence of increased LDL receptor activity during treatment since the FCR of LDL apo B remained unchanged.

A previous study of one premenopausal woman receiving a dose of estrogen (ethinyl estradiol, $100 \mu \mathrm{g} / \mathrm{d}$ ) that was about an order of magnitude higher in potency (26) than was used in the present study, detected no significant change in LDL apo B production, nor any significant reduction in the plasma con- 
centration of LDL protein, which reflects mainly apo B (10). Thus, the reductions in LDL apo B pool size and production rate in the present study were most likely mediated by the combined interactions of the estradiol-17 $\beta$ and $d l$-norgestrel.

We conclude that the favorable decreases in VLDL and LDL concentrations observed with this combined estrogen and progestin regimen reflect enhanced VLDL clearance and significantly reduced LDL production. These observations may be of clinical importance in the hormonal management of postmenopausal and other women with primary ovarian failure, especially with respect to the prevention of atherosclerosis $(8,11)$.

\section{Acknowledgments}

We thank Brian Sutherland and Shirley Koenig for expert technical assistance. We thank Dale Hobbs for assistance with the dietary assessment and dietary protocols. We are grateful to Elene Wolfe for preparing the artwork and typing the manuscript.

This work was supported by grant MT 4248 from the Medical Research Council of Canada.

\section{References}

1. Edman, C. D. 1983 . The climacteric. In The Menopause: Clinical Perspectives in Obstetrics and Gynecology. H. J. Buchsbaum, editor. Springer-Verlag New York, Inc., New York. 23-33.

2. Reyes, F. I., J. S. D. Winter, and C. Faiman. 1977. Pituitaryovarian relationships preceding the menopause. I. A cross-sectional study of serum follicle-stimulating hormone, luteinizing hormone, prolactin, estradiol, and progesterone levels. Am. J. Obstet. Gynecol. 129:557-564.

3. Rifkind, B. M., and P. Segal. 1983. Lipid Research Clinics Program reference values for hyperlipidemia and hypolipidemia. JAMA (J. Am. Med. Assoc.). 250:1869-1872.

4. Bengtsson, C., and O. Lindquist. 1978. Coronary heart disease during the menopause. In Coronary Heart Disease in Young Women. M. F. Oliver, editor. Churchill-Livingstone, Inc., New York. 234-242.

5. Havlik, R. J., and M. Feinleib, editors. 1979. Proceedings of the Conference on the Decline in Coronary Heart Disease Mortality. National Heart, Lung and Blood Institute. US Department of Health, Education, and Welfare, Bethesda, MD. NIH Publication No. 79-1610.

6. Johnson, R. E., and E. E. Specht. 1981. The risk of hip fracture in postmenopausal females with and without estrogen drug exposure. Am. J. Public Health. 71:138-144.

7. Zeigler, J. F., editor. 1981. Surveillance, epidemiology, and end results: incidence and mortality data, 1973-77. Natl. Cancer Inst. Monogr. 57. National Cancer Institute, Bethesda, MD. US Department of Health and Human Services. NIH Publication No. 81-2330.

8. Lapidus, L., C. Bengtsson, and O. Lindquist. 1985. Menopausal age and risk of cardiovascular disease and death. Acta Obstet. Gynecol. Scand. Suppl. 130:37-41.

9. Bush, T. L., L. D. Cowan, E. Barret-Connor, M. H. Criqui, J. M. Karon, R. B. Wallace, H. A. Tyroler, and B. M. Rifkind. 1983. Estrogen use and all-cause mortality: preliminary results from the Lipid Research Clinics Program follow-up study. JAMA (J. Am. Med. Assoc.). 249:903-906.

10. Schaefer, E. J., D. M. Foster, L. A. Zech, F. T. Lindgren, H. B. Brewer, Jr., and R. I. Levy. 1983. The effects of estrogen administration on plasma lipoprotein metabolism in premenopausal females. $J$. Clin. Endocrinol. \& Metab. 57:262-267.

11. Wolfe, B. M., and E. R. Plunkett. 1985. Reduction of LDL cholesterol in postmenopausal women by estradiol-17 $\beta$ and $d l$-norgestrel. Arteriosclerosis. 5:521a. (Abstr.)

12. Reardon, M. F., N. H. Fidge, and P. J. Nestel. 1978. Catabolism of very low density lipoprotein B apoprotein in man. J. Clin. Invest. 61:850-860.

13. Huff, M. W., P. M. Giovanetti, and B. M. Wolfe. 1984. Turnover of very low density lipoprotein apoprotein $B$ is increased by substitution of soybean protein for meat and dairy protein in the diets of hypercholesterolemic men. Am. J. Clin. Nutr. 39:888-897.

14. Huff, M. W., and D. E. Telford. 1985. Direct synthesis of low-density lipoprotein apoprotein B in the miniature pig. Metab. Clin. Exp. 34:36-42.

15. Khokha, R., M. W. Huff, and B. M. Wolfe. 1986. Divergent effects of $d$-norgestrel on the metabolism of rat very low density and low density apolipoprotein B. J. Lipid Res. 27:699-705.

16. Havel, R. J., H. A. Eder, and J. H. Bragdon. 1955. The distribution and chemical composition of ultracentrifugally separated lipoproteins in human serum. J. Clin. Invest. 34:1345-1353.

17. Huff, M. W., D. E. Telford, K. Woodcroft, and W. L. P. Strong. 1985. Mevinolin and cholestyramine inhibit the direct synthesis of low density lipoprotein apolipoprotein B in miniature pigs. J. Lipid Res. 26:1175-1186.

18. Goodman, D. S., R. P. Noble, and R. B. Dell. 1973. Three-pool model of the long-term turnover of plasma cholesterol in man. J. Lipid Res. 14:178-188.

19. Skinner, S. M., R. E. Clark, N. Baker, and R. A. Shipley. 1959. Complete solution of the three-compartment model in steady state after single injection of radioactive tracer. Am. J. Physiol. 198:238244.

20. Gurpide, E., J. Mann, and E. Sandberg. 1964. Determination of kinetic parameters in a two-pool system by administration of one or more tracers. Biochemistry. 3:1250-1255.

21. Nestel, P. J., M. F. Reardon, and N. H. Fidge. 1979. Very low density lipoprotein B-apoprotein kinetics in human subjects: relationships between pool size, flux, and removal rate. Circ. Res. 45:35-41.

22. Goodman, D. S., and R. P. Noble. 1968. Turnover of plasma cholesterol in man. J. Clin. Invest. 47:231-241.

23. Zilversmit, D. B. 1960 . The design and analysis of isotope experiments. Am. J. Med. 29:832-848.

24. Goldberg, I. J., N. A. Le, H. N. Ginsberg, J. Paterniti, Jr., and W. Virgil Brown. 1983. Metabolism of apoprotein B in cynomologous monkey: evidence for independent production of low-density lipoprotein B. Am. J. Physiol. 244:E196-E201.

25. Snedecor, G. W., and W. G. Cochran. 1967. The comparison of two samples. In Statistical Methods. Iowa State University Press, Ames, IA. Sixth ed. 94-97, 114.

26. Upton, G. V. 1984. Therapeutic considerations in the management of the climateric: a critical analysis of prevalent treatments. $J$. Reprod. Med. 29:71-80.

27. Taves, E. H. 1987. Effect of various estradiol preparations and of levonorgestrel on lipid metabolism in the rat. M.Sc. thesis. The University of Western Ontario, London, Ontario, Canada. 110 pp.

28. Khokha, R., and B. M. Wolfe. 1984. Hypotriglyceridemic effects of levonorgestrel in rats. Atherosclerosis. 52:329-338.

29. Khokha, R., P. A. Walton, F. Possmayer, and B. Wolfe. 1987. Effects of levonorgestrel on enzymes responsible for synthesis of triglycerides in rat liver. Biochim. Biophys. Acta. 918:120-125.

30. Tikkanen, M. J., E. A. Nikkila, T. Kuusi, and S. Sipinen. 1981. Differential effects of two progestins on plasma high density lipoprotein $\left(\mathrm{HDL}_{2}\right)$ and postheparin plasma hepatic lipase activity. Atherosclerosis. 40:365-369.

31. Nicoll, A., and B. Lewis. 1980. Evaluation of the roles of lipoprotein lipase and hepatic lipase in lipoprotein metabolism: in vivo and in vitro studies in man. Eur. J. Clin. Invest. 10:487-495.

32. Reardon, M. F., M. E. Poapst, and G. Steiner. 1982. The independent synthesis of intermediate density lipoproteins in Type III hyperlipoproteinemia. Metab. Clin. Exp. 31:421-427.

33. Windler, E. E. T., P. T. Kovanen, Y.-S. Chao, M. S. Brown, R. J. Havel, and J. L. Goldstein. 1980. The estradiol-stimulated lipoprotein receptor of rat liver: a binding site that mediates the uptake of rat lipoproteins containing apoprotein B and E. J. Biol. Chem. 255:10464-10471. 